\title{
Swelling Degree of Carrageenan-Corncob Bead Gel in Various Media
}

\author{
Sperisa Distantina a,1,*, Saktika Rofi'ah Haryani a,2, Rif'ah Ulfatun Hasanah a,3, Mujtahid \\ Kaavessina ${ }^{\text {a,4 }}$ \\ ${ }^{a}$ Department of Chemical Engineering, Faculty of Engineering, Universitas Sebelas Maret Surakarta, Jl. Ir. Sutami 36 A Surakarta 57126 , Indonesia \\ ${ }^{1}$ sperisa_distantina@staff.uns.ac.id *; ${ }^{2}$ saktikarofiah@gmail.com; ${ }^{3}$ rifah.ulfatun@gmail.com; ${ }^{4}$ mkaavessina@ft.uns.ac.id \\ * corresponding author
}

\section{ARTICLE INFO}

Article history

Received February 26, 2021

Revised August 03, 2021

Accepted August 18, 2021

Keywords

Bead gel

Corncob

Carrageenan

Glutaraldehyde

Swelling

\section{ABSTRACT}

Bead hydrogels were prepared from carrageenan-corncob mixture by physically and chemically crosslinking. The aims are to investigate the effect of carrageenan-corncob weight ratio and glutaraldehyde crosslinking on the swelling degree properties. The mixture of various carrageenan-corncob weight ratio $(1: 2,1: 1,2: 1$, and 1:0) was dropped into $\mathrm{KCl}$ and $\mathrm{CaCl}_{2}$ solution and then the obtained bead gels was dried. The dried bead gel was crosslinked using glutaraldehyde 4\%. The swelling degree behavior of the bead gels were tested in distilled water, $0.1 \mathrm{M} \mathrm{NaCl}$, and synthetic urine. The bead gels based on the mixture of carrageenan-corncob exhibited the hydrogel property. The highest swelling degree is carrageenan-corncob bead gels in the ratio of 1:0. The highest swelling degree is found in the distilled water and the lowest is in the synthetic urine. The 4\% glutaraldehyde crosslinking does not show specific different results for carrageenan-corncob bead gels.

\section{Introduction}

Hydrogel is a hydrophilic polymer material that has the ability to expand in water, forms equilibrium state and has a high permeability [1]. The hydrophilic properties of hydrogels are influenced by groups $-\mathrm{OH},-\mathrm{COOH},-\mathrm{CONH}_{2},-\mathrm{NH}_{2}$ and $\mathrm{SO}_{3} \mathrm{H}$. Swelling ability of hydrogel is a response to external factors such as $\mathrm{pH}$, ion strength, temperature, and the electric field. It depends on the properties of the polymer chain and allows the hydrogel useful in applications such as controlled drug release, separation process, diapers, or agricultural applications [2].

Hydrogel can be prepared from various polymer. The nature polymer has fragile and unstable physical properties. Therefore, the polymer structure should be modified by crosslinking method [3] to gain hydrogel properties. Crosslinking modification serves to reduce the selectivity of the hydrogel due to excessive swell [4]. In this research, bead hydrogels were prepared based on the local natural polymer, namely polysaccharide mixture from carrageenan and corncob. The hydrogel can be synthesized into bead form through an inverse suspension crosslinking process. Hydrogel beads have good chemical stability and mechanical strength. In addition, the relatively large surface area makes hydrogel beads of the same size and shape the most promising material that can be used to remove heavy metal ions [5].

The carrageenan is often classified as iota ( 1$)$, kappa $(\kappa)$, and lamda $(\lambda)$ which consisting of sulfated and linear polysaccharide structures [6]. Kappa carrageenan is extracted from red seaweeds (Rhodophyta). This natural polymer consists of chains $(1,4)-3,6$-anhydrous-a-Dgalactopyranose and (1,3)-D-galactopyranose with some sulfate groups. Kappa carrageenan has the ability to form 
reversible gels. The hydroxyl and sulfate groups in the carrageenan structure cause this polymer to be hydrophilic and may be chemically binding to increase its stability in water [2].

Corncob is a renewable biomass containing lignocellulose. Most of the corncob have not been utilized efficiently. One of them, it is used as raw materials in making low-grade fuels, which causes a lot of waste of corncob resources [7]. Therefore, it is important to develop the use of corncob being a useful product. Corncob contains $30-40 \%$ of hemicellulose, $35-45 \%$ of cellulose, and $5-20 \%$ of lignin and it contains various function groups such as carboxyl, hydroxyl, phosphate, ether, and amino groups [8][9].

This research develops bead gel based on carrageenan and corncob. This material combination will be modified by physical and chemical crosslinking to form a hydrogel structure that has the ability to swell in distilled water, $\mathrm{NaCl}$ solution, and synthetic urine. In previous research [10], chemically crosslinking that using $4 \%$ of glutaraldehyde had the best bead gel resistance. Hence, this research uses the concentration to learn the swelling properties of carrageenan-corncob bead gels. Swelling shows the bead gels ability to expand because the solution enters the bead gel structure. The application of the bead gel based carrageenan-corncob as an absorbent, it is necessary to know how much the ability of the bead gel to expand in various media. The purposes of the research are to determine the effect of carrageenan-corncob weight ratio and glutaraldehyde crosslinking on the swelling degree behavior of the obtained bead gels in distilled water, $0.1 \mathrm{M} \mathrm{NaCl}$ solution, and synthetic urine. The value of swelling degree (SD) of bead gels is evaluated using equation (1).

$$
\mathrm{SD}=\frac{\mathrm{Mw}-\mathrm{Md}}{\mathrm{Md}}
$$

\section{Material and Method}

\subsection{Materials}

The carrageenan flour, corncob, and palm oil (Bimoli) were purchased from local market located in Madiun, Indonesia. Technical ethanol $96 \%$ wt was used. Potassium chloride $(\mathrm{KCl}), 25 \% \mathrm{wt}$ glutaraldehyde (GA), calcium chloride $\left(\mathrm{CaCl}_{2}\right)$, sodium chloride $(\mathrm{NaCl})$, sodium phosphate $\left(\mathrm{Na}_{3} \mathrm{PO}_{4}\right)$, and urea were procured from E. Merck. All chemicals were used without further purification. The materials shown in Figure 1.

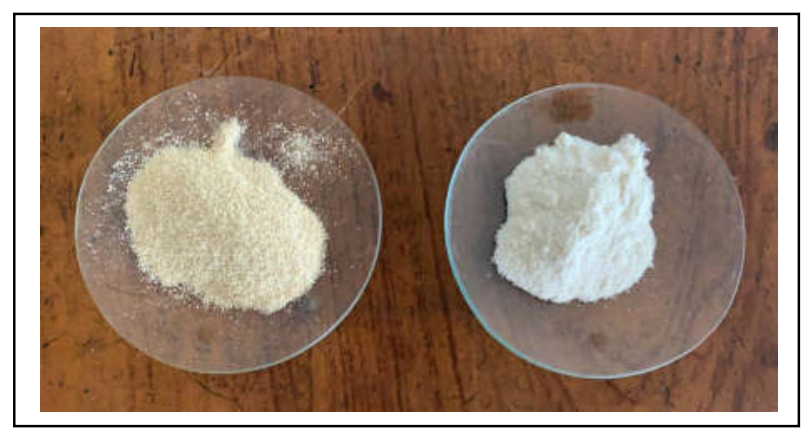

Fig. 1.Materials, (a) Corncob Flour and (b) Carrageenan Flour

\subsection{Corncob Flour Preparation}

The main raw materials used in this research are carrageenan and corncob flour. Corncob flour was made by drying corncobs in the sun. The dry corncobs were milled using a grinder. Corncobs that have been milled, then sieved using a 100 mesh sieve to obtain a smooth corncob flour.

\subsection{Bead Gel Preparation}

The steps of bead gel preparation from mixing of carrageenan and corncob flour, chemically crosslinking, and swelling test are shown in Figure 2.

The process of bead gel preparation was done by mixing the carrageenan and corncob flour into the distilled water until form a homogeneous solution with a concentration of $2 \%$. The various weight ratio of carrageenan and corncob were 1:2, 1:1, 2:1, and 1:0. The mixture was stirred using magnetic stirrer to keep the homogeneous solution and heated in $85^{\circ} \mathrm{C}$. Then, the solution was 
injected with a syringe $(5 \mathrm{~mL})$ to the surface of palm oil that coating the solution mixture of $0.2 \mathrm{M}$ $\mathrm{KCl}$ and $0.2 \mathrm{M} \mathrm{CaCl}_{2}$ solution in the ice handler. In this step, it performed physically crosslinking. After $25 \mathrm{~min}$, the bead gels were filtered and soaked in a $96 \%$ ethanol solution for 4 hours to reduce moisture content in the bead gel. Then, the bead gels were drained and dried at room temperature to a constant weight.

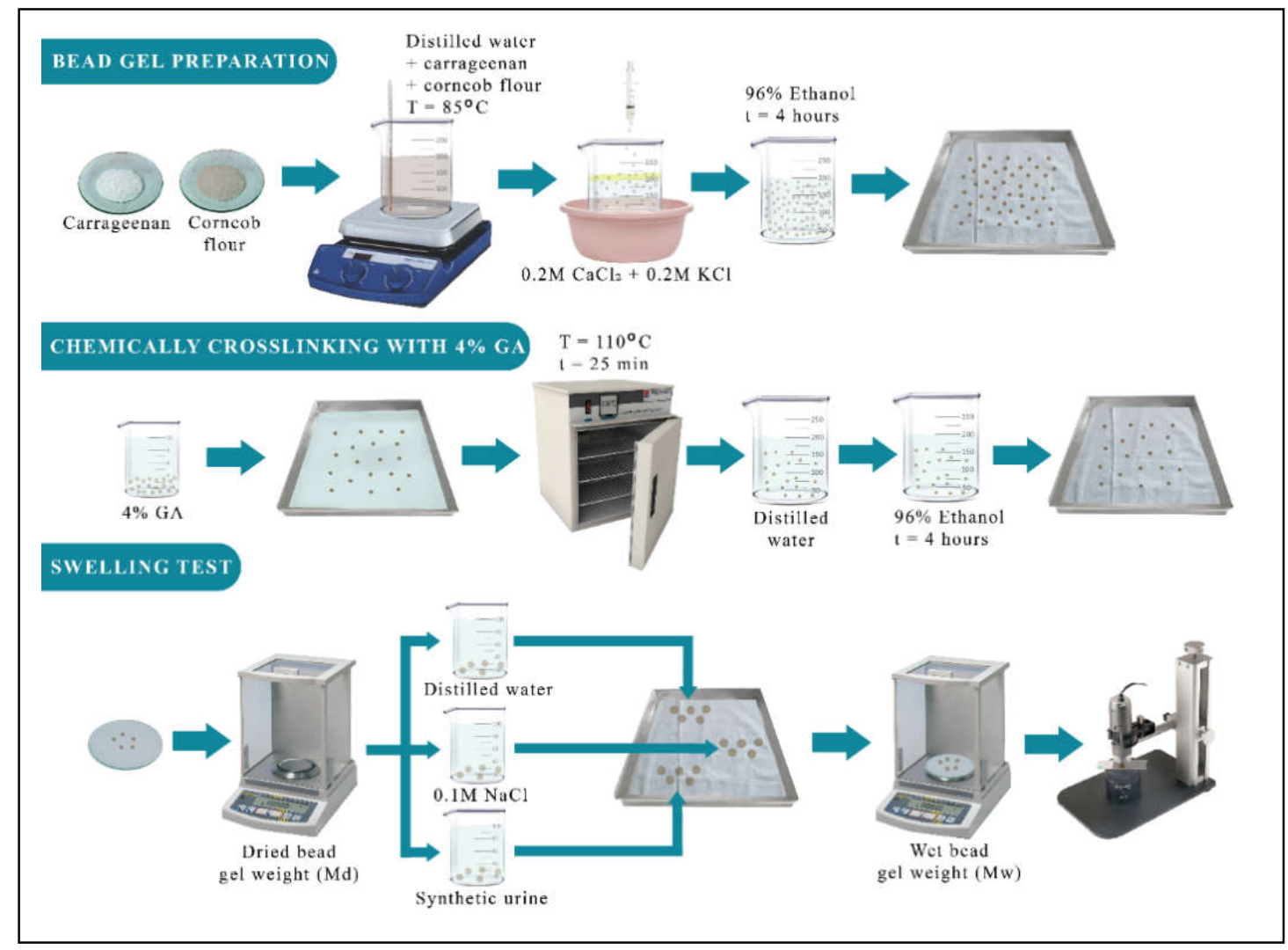

Fig. 2.Process of bead gel preparation, chemically crosslinking, and swelling test

\subsection{Chemically Crosslinking}

The polymer structure of the carragenan-corncob bead gel was chemically modified with a crosslinking using $4 \%$ GA. The $1.6 \mathrm{~mL}$ of $25 \%$ GA was dissolved into the distilled water up to 10 $\mathrm{mL}$. The bead gels were soaked into 4\% GA during 2 min. After draining, the bead gels were heated at $110^{\circ} \mathrm{C}$ for $25 \mathrm{~min}$. The bead gels were washed using distilled water, then soaked into $96 \%$ ethanol for 4 hours. The dried beads were referred to as crosslinked bead gels. The bead gel code in this research shown in Table 1.

Table 1. The Sample Codes of Carrageenan-Corncob Bead Gel

\begin{tabular}{ccc}
\hline Code & $\begin{array}{c}\text { Weight Ratio of } \\
\text { Carrageenan:Corncob }\end{array}$ & $\begin{array}{c}\text { Chemically Crosslinking } \\
\text { Treatment }\end{array}$ \\
\hline A & $1: 2$ & No \\
A $^{*}$ & $1: 2$ & Yes \\
B & $1: 1$ & No \\
B $^{*}$ & $1: 1$ & Yes \\
C & $2: 1$ & No \\
C $^{*}$ & $2: 1$ & Yes \\
D & $1: 0$ & No \\
D $^{*}$ & $1: 0$ & Yes \\
\hline
\end{tabular}

\subsection{Swelling Test}

Swelling test for 8 bead gel variants of carrageenan-corncob were carried out in the 3 different media, namely distilled water, $0.1 \mathrm{M} \mathrm{NaCl}$ solution, and synthetic urine. The $0.1 \mathrm{M} \mathrm{NaCl}$ solution 
was made by dissolving $0.585 \mathrm{~g}$ of $\mathrm{NaCl}$ crystals with distilled water up to a volume of $100 \mathrm{~mL}$. Whereas, the synthetic urine solution was made by dissolving as much as $2.43 \mathrm{~g}$ of urea, $0.6 \mathrm{~g}$ of $\mathrm{KCl}, 1 \mathrm{~g} \mathrm{NaCl}$, and $0.64 \mathrm{~g} \mathrm{Na}_{3} \mathrm{PO}_{4}$ into $100 \mathrm{~mL}$ distilled water. Furthermore, the mixture was stirred until homogeneous. Then, the $\mathrm{pH}$ of both solutions could be measured by using $\mathrm{pH}$ indicator. Swelling test of the bead gel was done by soaking 5 grains of bead gels with similar size into each media until 4 hours. Before soaking, 5 grains of dried bead gels were weighed firstly and expressed as dry weight $(\mathrm{Md})$. After being immersed in distilled water, $0.1 \mathrm{M} \mathrm{NaCl}$, and synthetic urine, the size of bead gels would be bigger. The bead gels were weighed every 30 min until a constant weight and expressed as a wet weight (Mw). Furthermore, swelling degree (SD) was calculated by using the equation (1). Each step of the swelling test was repeated at least twice and the average value was used to display the data.

\subsection{Morphological Analysis}

Morphological analysis was performed before and after swelling test. The dried bead was taken with tweezer and then analyzed using a dino-lite digital microscope at the same magnification for each sample to saw the change in bead gel size.

\section{Results and Discussion}

Swelling test for 8 variations of the carrageenan-corncob bead gel was carried out in 3 media, namely distilled water, $0.1 \mathrm{M} \mathrm{NaCl}$ solution, and synthetic urine. The difference ratio of carrageenancorncob to determine which bead gel has the most optimal swelling degree. Swelling degree in salt solution is very important in many practices such as personal hygiene products and water release systems in agriculture, while distilled water is a good solvent compared to all chemical liquids in general. Meanwhile, the swelling degree of bead gel in synthetic urine shows that this bead gel can be applied in everyday life, one of them is for diapers.

Figure 3 shows the SDs of bead gels in the various media. The changes of bead gels size in distilled water, $0.1 \mathrm{M} \mathrm{NaCl}$ solution, and synthetic urine can be seen in the Table 2, 3, and 4 . Before swelling, a dry bead gel had a diameter of approximately 2-3 $\mathrm{mm}$. After swelling, the bead gel would be bigger in size. This results show that the carrageenan-corncob mixture has the ability to act as a hydrogel in the form of a gel bead using the oil and $\mathrm{KCl}-\mathrm{CaCl}^{2}$ solution method.

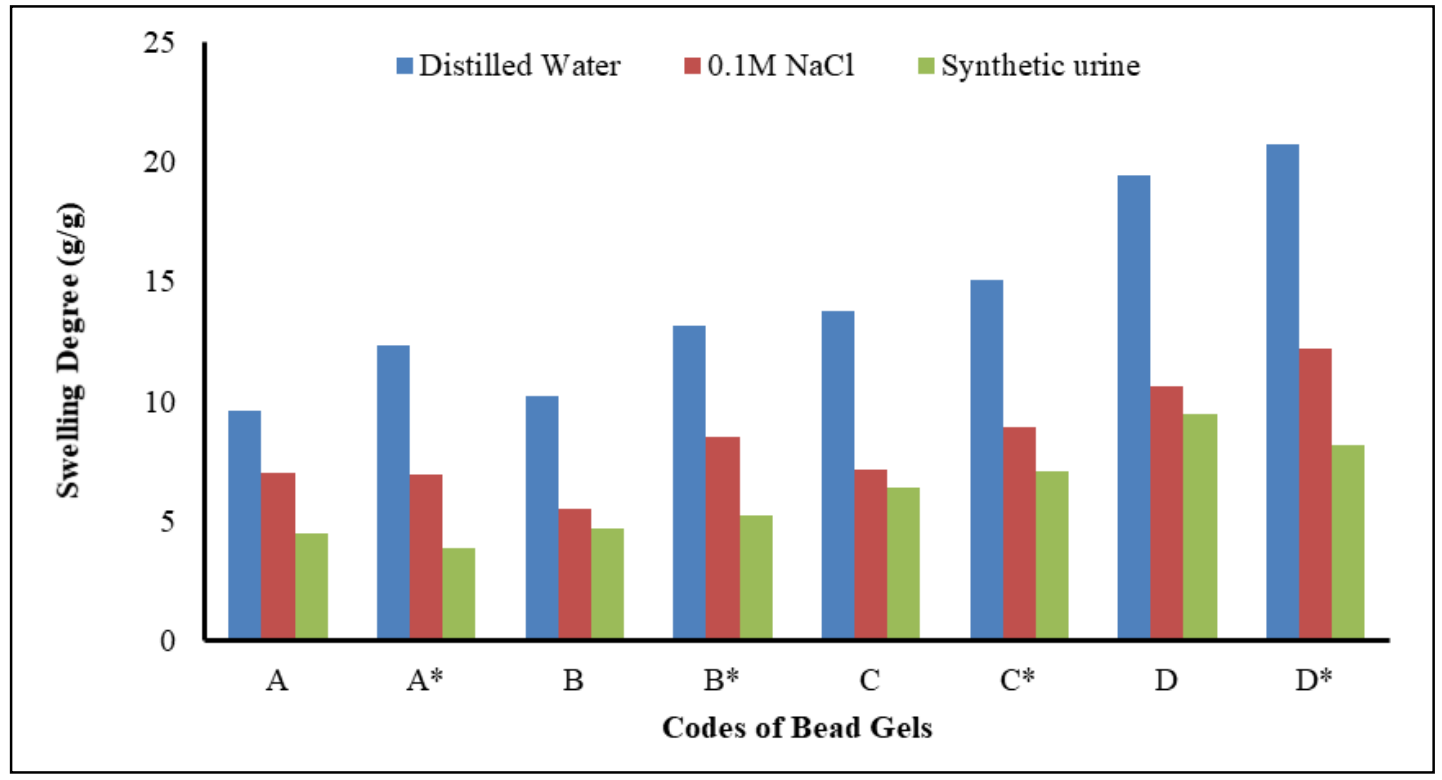

Fig. 3. Swelling degree of bead gels in various media

From Figure 3, the bead gel which has more corncob flour shows a small SD ratio. Moreover, the bead gel which has more carrageenan composition than corncob has higher SD in various media. It means that adding carrageenan in the bead gel mixture will increase SD. This is caused by the carrageenan that consists of polymer chains containing more hydrophilic charged groups than in corncob. The sulfate groups in carrageenan chain will be deprotonated in a neutral $\mathrm{pH}$ system and 
produce an $\mathrm{OSO}^{3-}$ ionic group. These adjacent negatively charged groups cause electrostatic repulsion driving the distance between the chains to increase and become more permeable so that a lot of water can penetrate the network. The swelling degree of carrageenan based hydrogels can be induced through stimuli such as changes in $\mathrm{pH}$ and salinity [11]. The maximum degree of swelling increases with the long sub-chains and the inter-crosslinking chain lengths.

The glutaraldehyde crosslinking treatment was not significantly influence to the SDs in various media (Figure 3). Based on the result of dino-lite test shown in Table 2, 3, and 4, both crosslinked bead gels and noncrosslinked bead gels expressed almost the same color and size after being swelled in distilled water, $0.1 \mathrm{M} \mathrm{NaCl}$ solution, and synthetic urine. It can be due to the bead gel hydrophilic groups that first bind to the $\mathrm{K}^{+}$and $\mathrm{Ca}^{2+}$ cations when physically cross-linked.

Table 2. The vision under the digital microscope (dino-lite) of the bead gels morphology in distilled water

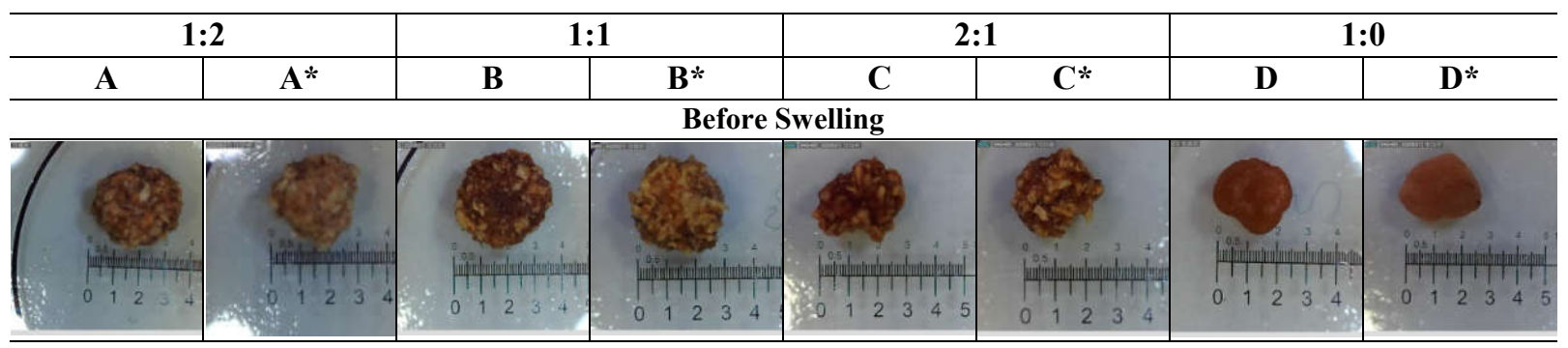

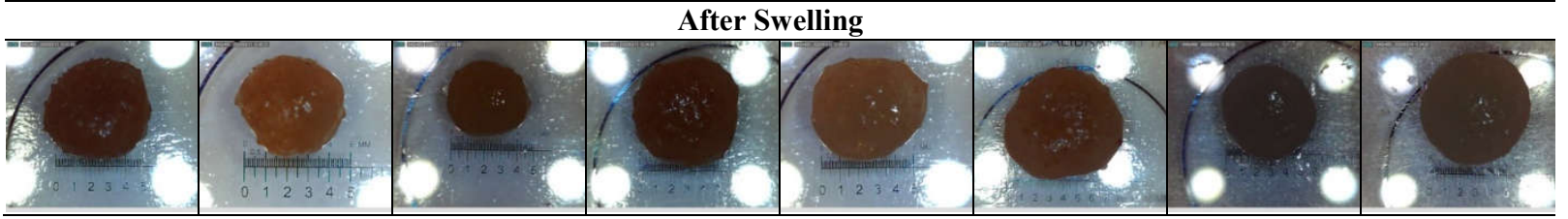

Table 3. The vision under the digital microscope (dino-lite) of the bead gels morphology in $\mathrm{NaCl}$ solution

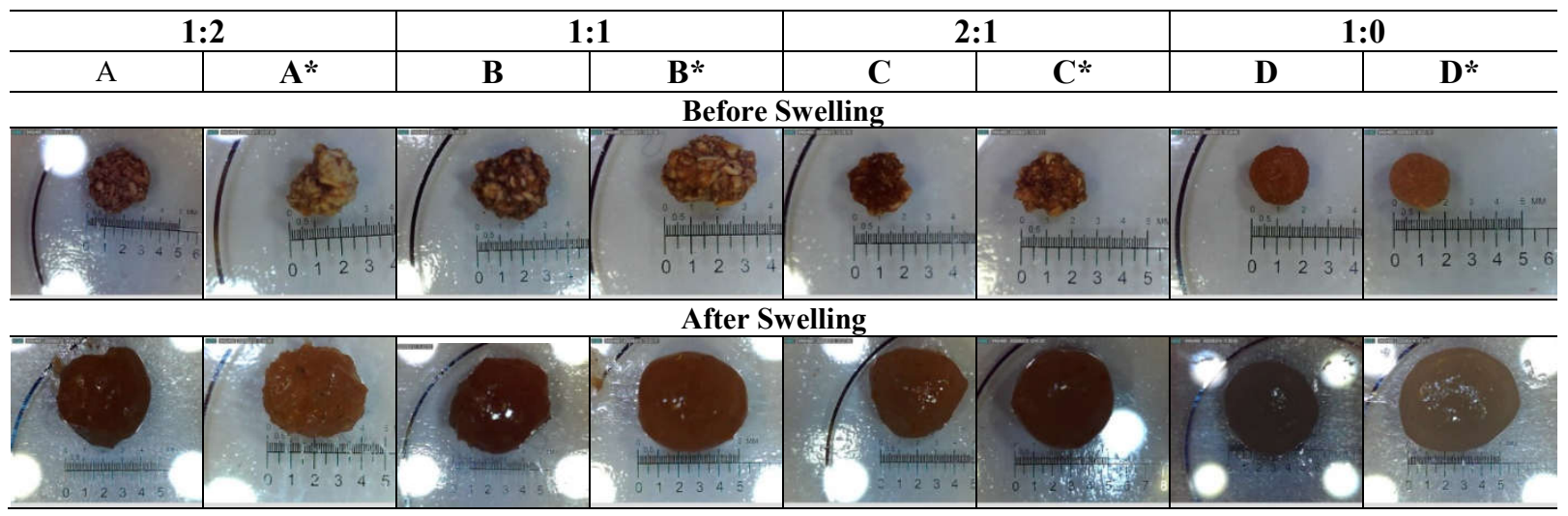

Table 4. The vision under the digital microscope (dino-lite) of the bead gels morphology in synthetic urine

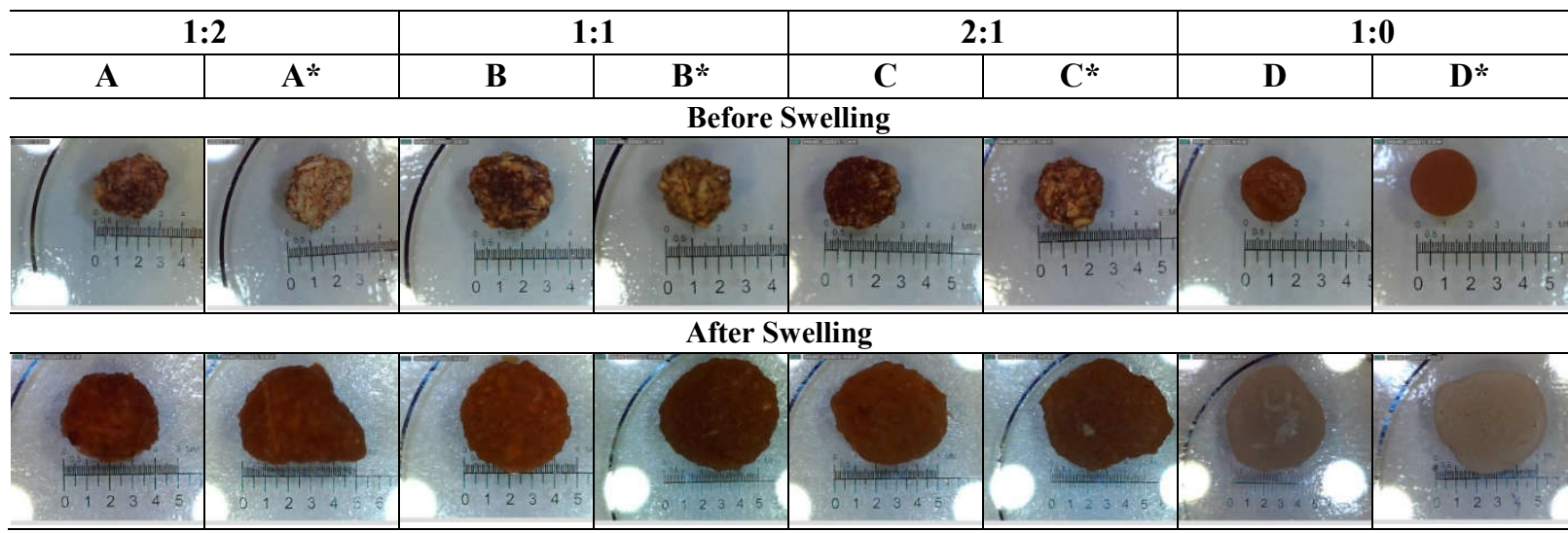


In distilled water, all bead gels exhibited highest SD compared to other media (Table 2). The bead gels in distilled water destroyed in 2 hours. The highest SD in this media is 20.7. Bead gels has hydrophilic properties, such as - $\mathrm{OH}$ groups. Interaction between the oppositely charged group in distilled water and polymer forms hydrogen bonds. This causes the highest SD.

Besides in distilled water, the bead gel also conducted in $0.1 \mathrm{M} \mathrm{NaCl}$ solution with $7 \mathrm{pH}$. In this media, carrageenan-corncob bead gels swelled 7-12 times (Table 3) and destroyed about 1.5 hours. The SDs in salt solution are lower than in distilled water because the anionic groups in the hydrogel are filtered out by $\mathrm{Na}^{+}$ions. As a result, the anionic groups in the hydrogel change to a denser matrix so that the SD is small [11].

The SDs of bead gels in synthetic urine are shown in Table 4. In this media, the SD of bead gel is.5. This is the lowest SD compared to distilled water and $0.1 \mathrm{M} \mathrm{NaCl}$. However, it has the best stable form. Within 24 hours, the bead gel was not destroyed. The low SD of bead gels in urine is caused by the difference between the concentration of mobile ions in the bead gels and in the urine [12]. Synthetic urine contains more ionic groups, namely $\mathrm{K}^{+}, \mathrm{Na}^{+}$, and $\mathrm{Ca}^{2+}$. This results in the hydrogel matrix becoming more denser so that the SDs tends to be small. The more anionic groups in synthetic urine resulted in the smallest SDs in this medium. The same trends of non-monotonic behavior in the present research were also found in hydrogels of a novel corncob-based semi-IPN hydrogel [13]. According to the research [13], corncob based hydrogel can expand in $\mathrm{KCl}, \mathrm{NaCl}$, and $\mathrm{CaCl}_{2}$ soluton. It was possible that $\mathrm{K}^{+}$and $\mathrm{Ca}^{2+}$ in synthetic urine have bonded to the hydroxyl and carboxyl group in the polymer mixture of the carrageenan-corncob bead gel that made this bead gel has small SD.

According to the swelling degree value in various media, it is said that the swelling ability of bead gels is influenced by type of cation charge in the solution. Hence, SD of bead gel decreases as the radius of cation increases. The cations also cause a decrease in anions electrostatic repulsion, so the osmotic pressure between the hydrogel system and the solution is also reduced [2].

\section{Conclusion}

The bead gels based on the mixture of carrageenan-corncob exhibited the hydrogel property. The highest SD is carrageenan-corncob bead gels in the ratio of 1:0. Bead gel in distilled water has the highest SD and the lowest is found in the synthetic urine. The 4\% GA crosslinking does not show specific different results of carrageenan-corncob bead gels properties compared with no crosslinking treatment.

\section{Notations}

$S D=$ swelling degree, $(\mathrm{g} / \mathrm{g})$

$M w=$ wet weight, $\mathrm{g}$.

$M d=$ dry weight, $\mathrm{g}$.

\section{Acknowledgment}

The authors would like to thank Chemical Engineering laboratory, Universitas Sebelas Maret for supporting facilities of this present works.

\section{References}

[1] A. Hekmat, A. Barati, E. V. Frahani, and A. Afraz, "Synthesis and analysis of swelling and controlled release behaviour of anionic sipn acrylamide based hydrogels," World Acad. Sci. Eng. Technol., vol. 56, no. 8, pp. 96-100, 2009, doi: 10.5281/zenodo.1074490.

[2] S. Distantina, F. Fadilah, M. Kaavessina, and A. Material, "Swelling behaviour of kappa carrageenan hydrogel in neutral salt solution," Int. J. Chem. Mol. Nucl. Mater. Metall. Eng., vol. 10, no. 8, pp. 917-920, 2016.

[3] Erizal, P. D.P., G. Sulistioso, Sudirman, J. Z., and Hariyanti, "Sintesis dan karakterisasi biodegradabel hidrogel superabsorben poli ( kalium akrilat ) -g- glukomanan dengan teknik iradiasi gamma,” J. Sains Mater. Indones., vol. 19, no. 1, pp. 32-38, 2017.

[4] M. Alauhdin and N. Widiarti, "Sintesis Dan Modifikasi Lapis Tipis Kitosan-Tripolifosfat," J. MIPA Unnes, vol. 37, no. 1, p. 113729, 2014.

[5] Z. Yang, H. Peng, W. Wang, and T. Liu, "Crystallization behavior of poly( $\varepsilon$-caprolactone)/layered 
double hydroxide nanocomposites," J. Appl. Polym. Sci., vol. 116, no. 5, pp. 2658-2667, 2010, doi: 10.1002/app.

[6] S. B. R. Berton et al., "Properties of a commercial $\kappa$-carrageenan food ingredient and its durable superabsorbent hydrogels," Carbohydr. Res., vol. 487, p. 107883, 2020, doi: 10.1016/j.carres.2019.107883.

[7] X. Yao, K. Xu, and Y. Li, "Physicochemical properties and possible applications of waste corncob fly ash from biomass gasification industries of China," BioResources, vol. 11, no. 2, pp. 3783-3798, 2016, doi: 10.15376/biores.11.2.3783-3798.

[8] A. Kawee-Ai et al., "Eco-friendly processing in enzymatic xylooligosaccharides production from corncob: Influence of pretreatment with sonocatalytic-synergistic Fenton reaction and its antioxidant potentials," Ultrason. Sonochem., vol. 31, pp. 184-192, 2016, doi: 10.1016/j.ultsonch.2015.12.018.

[9] L. Xie, M. Liu, B. Ni, and Y. Wang, "Utilization of wheat straw for the preparation of coated controlled-release fertilizer with the function of water retention," J. Agric. Food Chem., vol. 60, no. 28, pp. 6921-6928, 2012, doi: 10.1021/jf3001235.

[10] R. A. Lestary, L. N. Jazlina, and S. Distantina, "Bead Gel sebagai Controlled Release Urea : Pengaruh Konsentrasi Crosslinker Glutaraldehid," Chem. J. Tek. Kim., vol. 5, no. 1, p. 13, 2018, doi: 10.26555/chemica.v5i1.9694.

[11] R. Zhang, M. Tang, A. Bowyer, R. Eisenthal, and J. Hubble, "A novel pH- and ionic-strengthsensitive carboxy methyl dextran hydrogel," Biomaterials, vol. 26, no. 22, pp. 4677-4683, 2005, doi: 10.1016/j.biomaterials.2004.11.048.

[12] H. A. Abd El-Rehim, E. S. A. Hegazy, and H. L. Abd El-Mohdy, "Radiation synthesis of hydrogels to enhance sandy soils water retention and increase plant performance," J. Appl. Polym. Sci., vol. 93, no. 3, pp. 1360-1371, 2004, doi: 10.1002/app.20571.

[13] P. Wen, Y. Han, Z. Wu, Y. He, B. C. Ye, and J. Wang, "Rapid synthesis of a corncob-based semiinterpenetrating polymer network slow-release nitrogen fertilizer by microwave irradiation to control water and nutrient losses," Arab. J. Chem., vol. 10, no. 7, pp. 922-934, 2017, doi: 10.1016/j.arabjc.2017.03.002. 